\title{
Elevation angle alignment of quasi optical receiver mirrors of collective Thomson scattering diagnostic by sawtooth measurements
}

Moseev, D.; Meo, Fernando; Korsholm, Søren Bang; Bindslev, Henrik; Furtula, V.; Kantor, M.; Leipold, Frank; Michelsen, Poul; Nielsen, Stefan Kragh; Salewski, Mirko

Total number of authors:

11

Published in:

Review of Scientific Instruments

Link to article, DOI:

$10.1063 / 1.4737387$

Publication date:

2012

Document Version

Publisher's PDF, also known as Version of record

Link back to DTU Orbit

Citation (APA):

Moseev, D., Meo, F., Korsholm, S. B., Bindslev, H., Furtula, V., Kantor, M., Leipold, F., Michelsen, P., Nielsen, S. K., Salewski, M., \& Stejner Pedersen, M. (2012). Elevation angle alignment of quasi optical receiver mirrors of collective Thomson scattering diagnostic by sawtooth measurements. Review of Scientific Instruments, 83, 10E337. https://doi.org/10.1063/1.4737387

\section{General rights}

Copyright and moral rights for the publications made accessible in the public portal are retained by the authors and/or other copyright owners and it is a condition of accessing publications that users recognise and abide by the legal requirements associated with these rights.

- Users may download and print one copy of any publication from the public portal for the purpose of private study or research.

- You may not further distribute the material or use it for any profit-making activity or commercial gain

- You may freely distribute the URL identifying the publication in the public portal 


\section{AIP Ranteret Scientific Instruments}

\section{Elevation angle alignment of quasi optical receiver mirrors of collective Thomson scattering diagnostic by sawtooth measurements}

D. Moseev, F. Meo, S. B. Korsholm, H. Bindslev, V. Furtula et al.

Citation: Rev. Sci. Instrum. 83, 10E337 (2012); doi: 10.1063/1.4737387

View online: http://dx.doi.org/10.1063/1.4737387

View Table of Contents: http://rsi.aip.org/resource/1/RSINAK/v83/i10

Published by the American Institute of Physics.

\section{Related Articles}

Spectral emission measurements of lithium on the lithium tokamak experiment Rev. Sci. Instrum. 83, 10D537 (2012)

Concept to diagnose mix with imaging $\mathrm{x}$-ray Thomson scattering Rev. Sci. Instrum. 83, 10E534 (2012)

Thomson scattering in short pulse laser experiments Phys. Plasmas 19, 083302 (2012)

Anisotropic electron temperature measurements without knowing the spectral transmissivity for a JT-60SA Thomson scattering diagnostic

Rev. Sci. Instrum. 83, 10E346 (2012)

Development of a diagnostic technique based on Cherenkov effect for measurements of fast electrons in fusion devices

Rev. Sci. Instrum. 83, 083505 (2012)

\section{Additional information on Rev. Sci. Instrum.}

Journal Homepage: http://rsi.aip.org

Journal Information: http://rsi.aip.org/about/about_the_journal

Top downloads: http://rsi.aip.org/features/most_downloaded

Information for Authors: http://rsi.aip.org/authors

\section{ADVERTISEMENT}

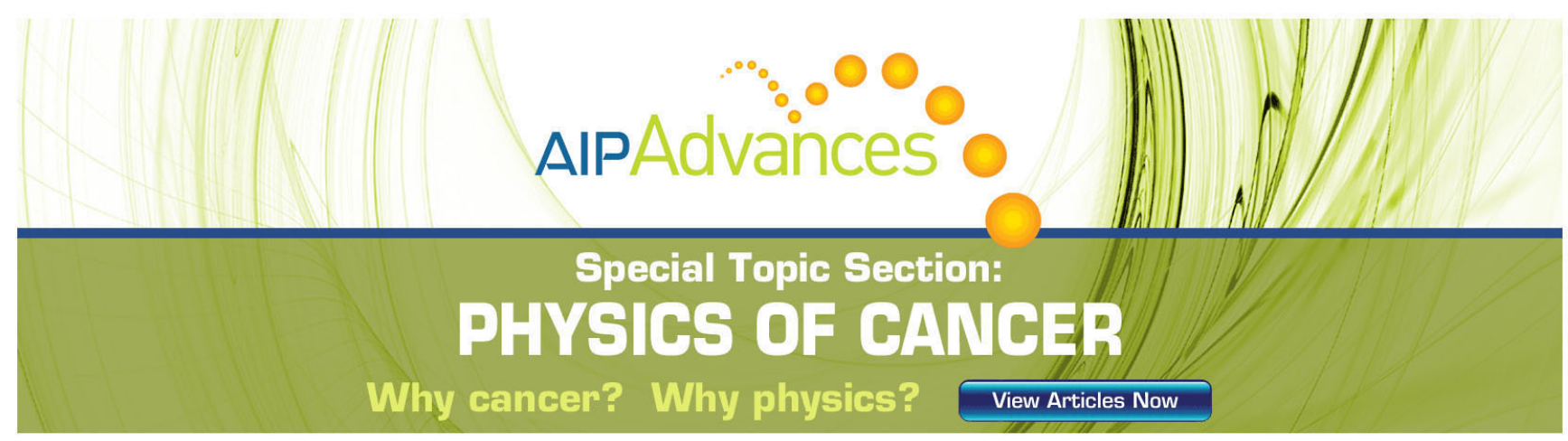




\title{
Elevation angle alignment of quasi optical receiver mirrors of collective Thomson scattering diagnostic by sawtooth measurements ${ }^{a)}$
}

\author{
D. Moseev, ${ }^{1,2, b)}$ F. Meo, ${ }^{3}$ S. B. Korsholm, ${ }^{3}$ H. Bindslev, ${ }^{4}$ V. Furtula, ${ }^{5}$ M. Kantor, ${ }^{1,6,7}$ \\ F. Leipold, ${ }^{3}$ P. K. Michelsen, ${ }^{3}$ S. K. Nielsen, ${ }^{3}$ M. Salewski, ${ }^{3}$ and M. Stejner ${ }^{3}$ \\ ${ }^{1}$ FOM DIFFER - Dutch Institute for Fundamental Energy Research, Association EURATOM-FOM, \\ Nieuwegein, The Netherlands \\ ${ }^{2}$ Max-Planck-Institut für Plasmaphysik, Euratom Association-IPP, 85748 Garching, Germany \\ ${ }^{3}$ Association EURATOM - DTU, Department of Physics, Technical University of Denmark, Ris $\phi$ Campus, \\ 4000 Roskilde, Denmark \\ ${ }^{4}$ Faculty of Science and Technology, Aarhus University, Ny Munkegade 120, DK-8000 Aarhus C, Denmark \\ ${ }^{5}$ Chalmers University of Technology, SE-412 96 Gothenburg, Sweden \\ ${ }^{6}$ FZ Jülich GmbH, EURATOM, Trilateral Euregio Cluster, D-52425 Jülich, Germany \\ ${ }^{7}$ Ioffe Institute, RAS, Saint Petersburg 194021, Russia
}

(Presented 8 May 2012; received 7 May 2012; accepted 4 June 2012; published online 31 July 2012)

\begin{abstract}
Localized measurements of the fast ion velocity distribution function and the plasma composition measurements are of significant interest for the fusion community. Collective Thomson scattering (CTS) diagnostics allow such measurements with spatial and temporal resolution. Localized measurements require a good alignment of the optical path in the transmission line. Monitoring the alignment during the experiment greatly benefits the confidence in the CTS measurements. An in situ technique for the assessment of the elevation angle alignment of the receiver is developed. Using the CTS diagnostic on TEXTOR without a source of probing radiation in discharges with sawtooth oscillations, an elevation angle misalignment of $0.9^{\circ}$ was found with an accuracy of $0.25^{\circ}$. () 2012 American Institute of Physics. [http://dx.doi.org/10.1063/1.4737387]
\end{abstract}

Fast ion physics is vital for fusion research since energetic particles influence the fusion yield, drive and suppress instabilities, and carry a significant part of the plasma current. Thus, resolving fast ion dynamics is important for the future success of ITER. The microwave-based collective Thomson scattering (CTS) diagnostic is able to perform spatially and temporally resolved measurements of the projection of the fast ion velocity distribution function along a direction determined by the scattering geometry. ${ }^{1-7}$ In some machines CTS was used for ion temperature measurements. ${ }^{8-10}$ Additionally, sensitivity of high resolution scattering spectra at certain geometries to the isotope content of the plasma was demonstrated and exploited. ${ }^{1-15}$ In order to interpret the experimental results correctly, the optical paths in the transmission lines for probe and receiver have to be well aligned. We focus here on the receiver beam transmission line. This technique is an added value since the alignment check of the whole transmission system can be only monitored during the vessel openings. ${ }^{3}$

Therefore, in situ alignment checks during the experimental campaign greatly benefit the confidence in the measurements. The steerable mirror at the front-end portion of the receiver transmission line has two degrees of freedom: rotation about the vertical axis and about the horizontal axis. These are described by the elevation angle and the rotation angle, respectively (see Figure 1). The rotation and elevation

\footnotetext{
a) Contributed paper, published as part of the Proceedings of the 19th Topical Conference on High-Temperature Plasma Diagnostics, Monterey, California, May 2012.

b) Author to whom correspondence should be addressed. Electronic mail: d.moseev@differ.nl.
}

angles determine the location of the scattering volume and the projection angle $\phi$ which in turn determines the velocity space interrogation region. ${ }^{1}$ Overlap sweeps, ${ }^{7}$ in which the probing beam is fixed and receiver beam is swept across it, are used to maximize the scattering from the overlap volume (where the scattering measurements take place) and verify the rotation angle alignment. Due to the relative placement of the probing and receiver mirrors (one above another in TEXTOR), the overlap sweep is not sensitive to the quality of the elevation angle alignment. The technique described in this article allows an elevation angle alignment check during a single plasma discharge.

During normal CTS operation, the magnetic field is chosen such that the resonance layers of electron cyclotron emission (ECE) in the CTS receiver frequency bandwidth are located outside the plasma. This is done in order to avoid absorption of the probing radiation and to facilitate an ECE background subtraction. For the vertical alignment check, contrarily to the normal CTS operation, the magnetic field strength is lowered to ensure that ECE in the receiver bandwidth originates from resonance layers intersecting the core of the plasma, as illustrated in Figure 2.

The CTS receiver is operated as an ECE radiometer, i.e., without a source of the probing radiation. In this regime the diagnostic is sensitive to the local changes in electron temperature and so can detect sawtooth oscillations.

The sawtooth instability is triggered by the $\mathrm{m} / \mathrm{n}=1 / 1$ kink mode, therefore the instability occurs on the magnetic surface with the safety factor $q=1$. The sawtooth crash is caused by the reconnection of the magnetic field lines and results in a sudden drop of electron temperature and density in the plasma core, followed by a slow increase of the pa- 


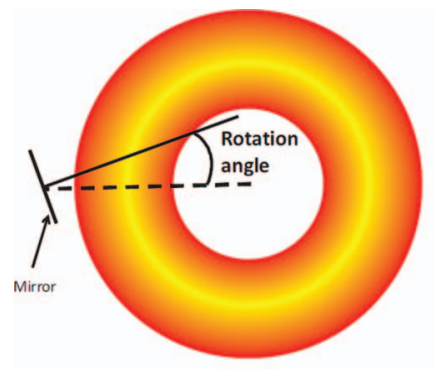

(a)

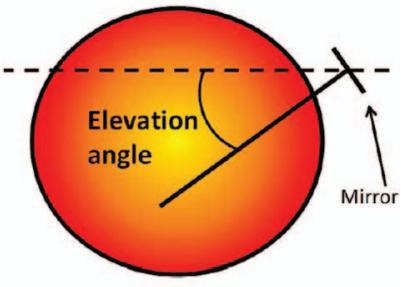

(b)
FIG. 1. Illustration of the geometrical angles which are used to describe the mirror setting. (a) A sketch of the top view of the tokamak, rotation angle is shown; (b) A sketch of the poloidal cross-section of the tokamak, elevation angle is shown.

rameters until the next sawtooth event is triggered. Outside the $q=1$ surface, inverted sawteeth are observed. They are characterized by sudden increase of electron density and temperature, caused by ejection of hot electrons from inside the $q=1$ surface. In TEXTOR, if no vertical shift is applied, the plasma is symmetric about the equatorial $(z=0)$ plane, see Figure 2. Therefore, the $q=1$ magnetic surface is also symmetric with respect to $z=0$. The CTS receiver, being a sensitive radiometer, is capable of detection of the position where the resonance layer intersects the $q=1$ magnetic surface. If the alignment is accurate, the ray-tracing technique which calculates the origin of the received radiation as a function of mirror position and plasma parameters should show that the position of the intersection points of the resonance layer with the $q=1$ surface are symmetric with respect to the $z$ $=0$ plane. This is based on incoherent Thomson scattering measurements in many TEXTOR discharges. In order to perform the measurements, the receiver mirror has to undergo an elevation angle scan across the poloidal cross-section of the plasma. Setting the rotation angle of the mirror to zero, the influence of refraction is reduced, and so are the uncertain-

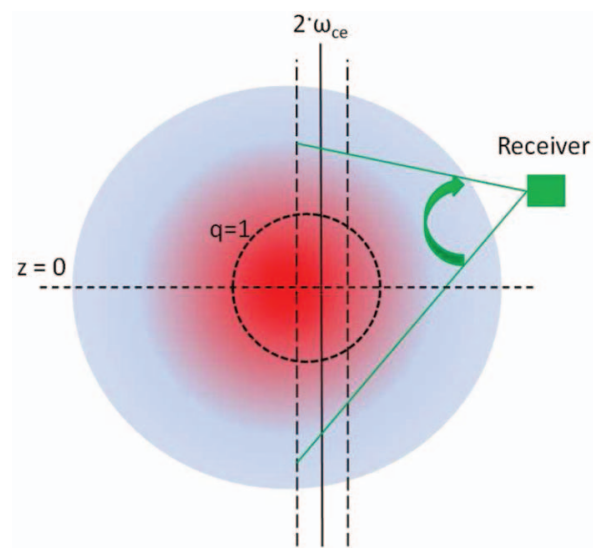

FIG. 2. Sketch illustrating a principle of post-factum elevation alignment check using the CTS receiver as an ECE radiometer. A boundary of the $q$ $=1$ magnetic surface is shown as black dashed circle; the horizontal dashed line denotes $z=0$ plane; the black vertical and dashed lines show the lower and upper limits of the receiver's bandwidth; the green box denotes a steerable mirror of the receiver, solid green lines represent the beam of electron cyclotron waves propagating into the receiver; the green arrow indicates the direction of the receiver mirror sweep.

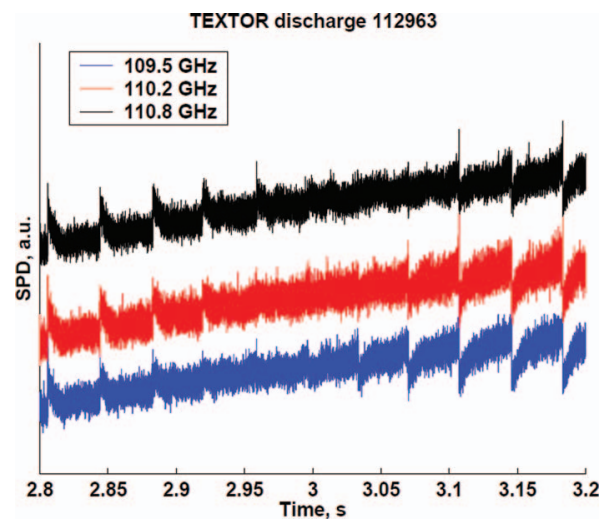

FIG. 3. SPD time traces of the CTS receiver channels 15 ( $109.5 \mathrm{GHz}), 23$ $(110.2 \mathrm{GHz})$, and $31(110.8 \mathrm{GHz})$ while crossing the $q=1$ surface from outside to inside. The disappearance of the inverted sawtooth signature and the appearance of the regular sawtooth signature in the channels have a time shift due to the different locations of the intersection region for different channels.

ties in plasma parameters for the ray-tracing. The polarizer mirrors are set to receive the second harmonic of ECE in the $\mathrm{X}$ mode. The scan should be performed slowly enough, so that the period of the sawtooth oscillations is much shorter than the passage time of the receiver beam past a given point in the resonance layer. In practice this means that the transition through the region in the vicinity of intersection between the resonance layer and the $q=1$ surface, where the sawteeth are not evident, should be longer than several sawtooth periods. This also requires that the plasma parameters are stable throughout the scan, so that the position of the $q=1$ surface does not change. Plasma parameters of TEXTOR discharge 112963 during the elevation angle scan $(2.5 \mathrm{~s}-4.5 \mathrm{~s})$ are the following: $\mathrm{I}_{\mathrm{p}}=370 \mathrm{kA}, \mathrm{B}_{\mathrm{t}}=1.9 \mathrm{~T}$, $\mathrm{n}_{\mathrm{e}}($ center $)=3.7 \times 10^{19} \mathrm{~m}^{-3}, \mathrm{~T}_{\text {sawtooth }}=37 \mathrm{~ms}$. $\mathrm{T}_{\text {sawtooth }}$ is the sawtooth period. At TEXTOR the evolution of the magnetic configuration could not be tracked by measurements. However, the sawtooth period is often used to conclude on the similarity of the experimental conditions. The sawtooth period in TEXTOR discharge 112963 during the measurement is constant within $4 \%$.

The CTS receiver at TEXTOR is equipped with 42 channels, each of them receiving radiation at different frequencies, which implies that the resonance layers for different channels are spatially separated and that during the sweep across the poloidal cross-section of the plasma, the transition through the $q=1$ surface should show at different times in each channel. Figure 3 shows spectral power density (SPD) time traces for three representative channels, no. 15, 23, and 31 during the crossing of the $q=1$ surface from outside to inside. One can see that the inverted sawtooth signature first disappears in channel 15, then 23, and later in channel 31. In the same ordering regular sawtooth signature appears in the channels.

There are a number of reasons why the transition between normal and inverted sawtooth is not abrupt. The first reason is geometrical. On the magnetic surface where $q=1$ exactly, electron temperature and density should not change at all. In the very proximity of the surface, changes are small. Second, the received beam is Gaussian and has a finite width. 


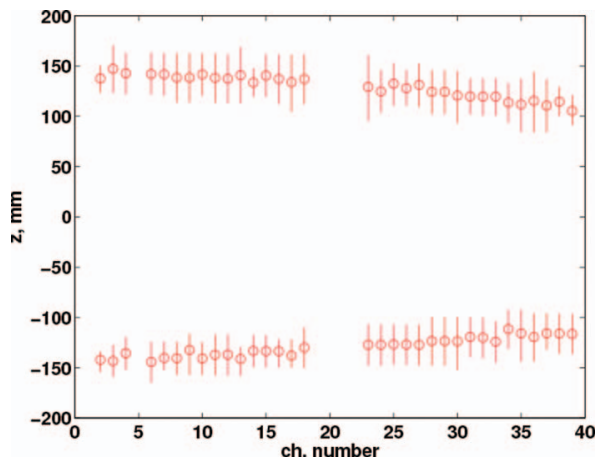

FIG. 4. Vertical position of the intersection position of the resonance layers for different channels as a function of channel number calculated by raytracing. Error-bars are calculated with the ray-tracing and correspond to the quiescent periods when no sawteeth could be detected.

This means that the received signal represents a weighted average of the emission over the beam width, so it is difficult to spot a precise location of the transition. An effect of a finite bandwidth of channels in the CTS receiver is negligible.

The location in the plasma, where the detected radiation originates from, is calculated using ray-tracing. The calculation is conducted independently for 33 CTS channels (the channels with large bandwidth, damaged channels, or channels with high attenuation are not considered). The centre of this transition time window between inverted and noninverted sawteeh corresponds to the elevation antenna angle where the centre of the beam intersects the $q=1$ surface. The duration of the period when no sawteeth are observed and the velocity of the scan set an error-bar on the vertical and angular position of the intersection location determined by raytracing. Figure 4 shows the calculated vertical positions of the intersection of the resonance layer for different channels as a function of the channel number (i.e., frequency), including the error-bars.

On TEXTOR, the magnetic axis is at the $z=0$ position, hence the calculated values in Figure 4 should be centered around $z=0$. However, the average calculated $z$-coordinate of all channel is $-27 \mathrm{~mm}$. The standard deviation is $\sigma_{z}=7 \mathrm{~mm}$, which is calculated by weighted averaging of the bisection points of all 33 channels:

$$
\begin{aligned}
& \bar{z}_{c}=\frac{\sum_{i=1: 33} z_{c, i} / \sigma_{i}^{2}}{\sum_{i=1: 33} 1 / \sigma_{i}^{2}} \\
& 1 / V=\sum_{i=1: 33} 1 / \sigma_{i}^{2} .
\end{aligned}
$$

Here $\bar{z}_{c}$ is a weighted average of the $z$-coordinates of the bisection points of individual channels, $z_{c, i}$ is a $z$-coordinate of the bisection point of channel $i, \sigma_{i}$ is a standard error of the $z$-coordinate of the bisection point of channel $i, V$ is a vari-

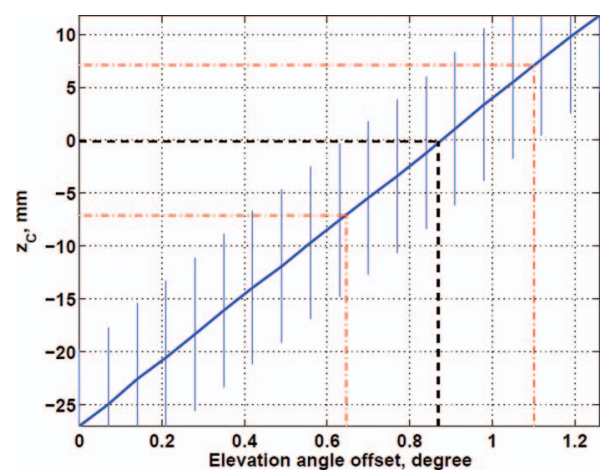

FIG. 5. Vertical position of the symmetry plane of the $q=1$ surface as a function of numerically introduced offset of the elevation angle. Errorbars on the vertical position of the symmetry plane are calculated as stated in Eq. (2).

ance of the average simulated $z$-coordinate of the bisection point.

Figure 5 shows the vertical location of the bisection point calculated by the ray-tracing code as a function of an offset in the elevation angle.

Error-bars on the vertical position of the bisection point are calculated as errors of the vertical locations of the bisection point deduced from the measurements of individual channels, see Eq. (2). One can see that if no vertical offset is applied, the bisection point is not located at $z=0 \mathrm{~m}$, as it should. However, when an offset of $0.9^{\circ}$ is applied, the bisection point of the $q=1$ plane is perfectly aligned with the equatorial plane of the tokamak. It implies that the front-end mirror has an elevation misalignment of $0.9^{\circ}$ with an accuracy of $0.25^{\circ}$. We note that these results do not rely on information from other sources about the location of the $q=1$ surface. Rather, they depend only on the symmetry of the $q=1$ surface about the $z=0$ plane.

The authors would like to express their gratitude to the TEXTOR team for its help in conducting the experiment and to Natalia Medissova for her help in improving the illustrations.

\footnotetext{
${ }^{1}$ M. Salewski et al., Nucl. Fusion 51, 083014 (2011).

${ }^{2}$ S. K. Nielsen et al., Nucl. Fusion 51, 063014 (2011).

${ }^{3}$ F. Meo et al., Rev. Sci. Instrum. 79, 10E501 (2008).

${ }^{4}$ M. Salewski et al., Nucl. Fusion 50, 035012 (2010).

${ }^{5}$ F. Meo et al., J. Phys.: Conf. Ser. 227, 012010 (2010).

${ }^{6}$ S. K. Nielsen et al., Plasma Phys. Controlled Fusion 52, 092001 (2010).

${ }^{7}$ S. K. Nielsen et al., Phys. Rev. E 77, 016407 (2008).

${ }^{8}$ M. Born, H. D. Dicken, J. Hackmann, and J. Uhlenbusch, Plasma Phys. Controlled Fusion 35, 391-396 (1993).

${ }^{9}$ E. V. Suvorov et al., Plasma Phys. Controlled Fusion 37, 1207-1213 (1995).

${ }^{10}$ R. Behn et al., Phys. Rev. Lett. 62, 2833-2836 (1989).

${ }^{11}$ S. B. Korsholm et al., Phys. Rev. Lett. 106, 165004 (2011).

${ }^{12}$ M. Stejner, S. K. Nielsen, H. Bindslev, S. B. Korsholm, and M. Salewski, Plasma Phys. Controlled Fusion 53, 065020 (2011).

${ }^{13}$ S. B. Korsholm et al., Rev. Sci. Instrum. 81, 10D323 (2010).

${ }^{14}$ M. Stejner et al., Rev. Sci. Instrum. 81, 10D515 (2010).

${ }^{15}$ M. Stejner et al., Plasma Phys. Controlled Fusion 54, 015008 (2012).
} 